\title{
CONSEQUENCES OF SICKNESS PRESENCE AND SICKNESS ABSENCE ON HEALTH AND WORK ABILITY: A SWEDISH PROSPECTIVE COHORT STUDY
}

\author{
KLAS GUSTAFSSON and STAFFAN MARKLUND
}

Karolinska Institutet, Stockholm, Sweden

Department of Clinical Neuroscience, Division of Insurance Medicine

\begin{abstract}
Objective: To determine whether self-reported sickness presence (SP) and self-reported sickness absence (SA) are specific risk factors for future health problems or reduced work ability in the active workforce. Materials and Methods: The study population consisted of a cohort based on a random sample $(n=2181)$ with data for 2004, 2005, and 2006. The subjects were employees aged from 25 to 50 years in 2004. Cross-tabulations were calculated to identify significant background factors (sex, age, education, socioeconomic position), work factors (work demands, control, adjustment latitude), and outcome factors. Block-wise multiple logistic regression analyses were performed for outcome factors (SP, SA, self-rated health, physical complaints, work ability, mental well-being). Results: SA and SP were found to have negative health consequences; this was particularly pronounced for those with frequent SP or SA. There was a dose-response relationship between the degree of SA, SP and the different health outcomes. The health risks remained, after control for background factors, prior working conditions and initial health. SP also appeared to lead to SA, whereas SA did not have a significant impact on future SP. Conclusions: The results suggest that both SP and SA are strong predictors of future poor health, physical complaints, low mental well-being and low work ability. The detrimental influence of frequent SP was most pronounced in relation to work ability and physical complaints, although all of the measured health factors were affected. The negative effects of SA on the different health outcomes were similar.
\end{abstract}

Key words:

Sickness absence, Sickness presence, Work ability, Health, Working conditions

\section{INTRODUCTION}

In recent years, there has been considerable expansion of research concerning sickness presence (SP), a phenomenon that entails people choosing to go to work despite being ill. New perspectives and developments have emerged, and a number of issues have become particularly prominent, namely the prevalence of SP in different occupational groups, the determinants of SP, and the effects of SP on productivity and health among employees [1-7]. Cross-sectional studies have shown that SP is positively correlated with illness [8-10] and with sickness absence (SA).

According to an American perspective, there is also a growing interest among employers and insurance companies to evaluate survey instruments that measure SP-induced,

This study was funded by the Swedish Council for Working Life and Social Research.

Received: October 7, 2010. Accepted: January 19, 2011.

Address reprint request to K. Gustafsson, Department of Clinical Neuroscience, Division of Insurance Medicine, Karolinska Institutet, SE-171 77 Stockholm, Sweden (e-mail: klas.gustafsson@ki.se). 
health-related reductions in productivity at work $[11,12]$. This increased focus on SP may be due to the fact that many companies in the United States do not offer sickness benefits for illness lasting up to three days.

Notably, research on SA has concentrated primarily on the causes, not the consequences, of such absence [13]. Nevertheless, a few studies have indicated negative outcomes related to SA, including inactivity, isolation, reduced well-being, as well as impaired self-image and career opportunities [14-16]. In Sweden, long-term SA has been found to increase the risk of adverse financial and social conditions [17], and also to have negative effects on leisure activities, sleep, and psychological well-being [18]. A causal analysis of SP and SA and their impact on health requires longitudinal studies and more complex analytical methods. Relevant issues in such research concern the relationships between SP and ill health, and between SP and SA. Thus far, only a few longitudinal investigations have examined health outcomes in that context.

A study by Kivimaki et al. [19] compared two groups of employees with poor health due to heart attacks: one comprising the individuals who had gone on sick leave, and the other including those who had continued to work as usual (i.e., SP). After controlling for some known risk factors for heart and vascular disease, it was observed that at threeyear follow-up the risk of heart attack had doubled in the SP group compared to the employees with moderate levels of sickness absence. However, Westerlund et al. [20] found no evidence that SP increased the risk of coronary heart disease over a two-year period. In a longitudinal investigation of a large random sample of the workforce in Denmark [21], it was noted that SP was related to longterm sickness absence. This was indicated by the observation that, after controlling for potential confounders, the risk of sick leave for more than two months was $74 \%$ higher among employees who had gone to work while ill more than six times in the year prior to the 18-month follow-up period. In the Netherlands, a three-wave study examining correlations between burnout, job demands, and SP [22] showed that high job demands led to more SP, and also that SP could be regarded as a risk-taking behavior that caused burnout and "depersonalization". Two recent longitudinal studies of employees in the public and the private sector in Sweden have indicated that SP is associated with negative health consequences and sick leave at a later stage $[23,24]$, and the cited authors concluded that overutilization of SP leads to deteriorated health.

There are also a few longitudinal studies in the literature that concern the effects of SA, one of which showed an excess risk of early death among employees with SA spells lasting one week or more over a three-year period [25]. Furthermore, based on the same cohort, Vahtera et al. [26] recently found an association between SA and future selfrated health.

Several problems arise when attempting to interpret the consequences of SP. One difficulty is that the decision to go to work despite illness may be related to the degree of poor health, and it is plausible that individuals who choose SP over SA are those whose ill health is less severe. It is also reasonable to assume that working conditions influence whether or not a person can work while ill, and that SP in particular will be influenced by the degree of control and flexibility the employee has at work. For these reasons, health status and working conditions should be taken into account when studying the outcomes of SP.

Some investigators have assumed that the causes of SP and SA are at least partly different, even though there are generally positive correlations between the two phenomena, indicating that the same individuals often have both SP and SA $[27,28]$.

The main purpose of the current study was to determine whether SP and SA are risk factors for future SA or SP, deterioration of health, or reduced work ability in the active workforce. To be able to assess the specific risks of SP and SA, a number of factors that are known to affect health and work ability were controlled for in the analyses. 


\section{MATERIALS AND METHODS}

\section{Participants and procedures}

The study population (the Swedish Working Life Cohort) consisted of a random sample comprising 5009 persons drawn from the Statistics Sweden's registers of the Swedish population (Figure 1). The subjects were employees aged 25-50 years in 2004. The data on the cohort at the beginning of 2004, 2005, and 2006 was gathered for analysis, and a longitudinal database on the health and social insurance information (LISA) was linked to the cohort for the period 1999-2006. The original data material was collected in two stages: first by telephone interviews and subsequently by asking the respondents to complete a postal questionnaire [29]. As SP and SA were in focus, individuals outside the labor market, as well as those who were unemployed, were excluded from this study. All in all, there were 2493, 2324, and 2198 working individuals who participated in the interviews and completed the questionnaire in 2004, 2005, and 2006, respectively.

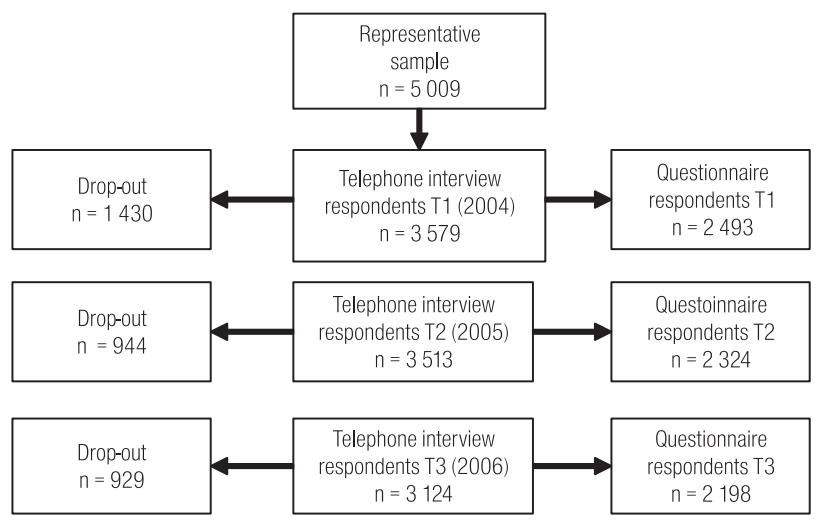

Fig. 1. Description of data collection for the Working Life Cohort.

\section{Measurements}

\section{Background factors}

The background factors used were sex, age, education and socioeconomic position. Age was broken down into five categories (25-30, 31-35, 36-40, 41-45, and 46-50), and education was considered in two categories (university or no university). Socioeconomic position (SEI) was derived from the participants' occupation and employment status, and was divided into three categories (blue-collar workers, white-collar workers, and professionals).

\section{Work factors}

The work-related factors used in the present study included work demands, control at work, and adjustment latitude at work. The factor "work demands" was measured using an index consisting of seven of the nine items suggested by Karasek and Theorell [30,31]: "work fast", "work hard", "enough time", "conflicting demands", "intense concentration", "task interrupted", and "hectic job". There was no information available on the proposed items "no excessive amount of work" and "have to wait for others". The index varied between 1 and 5, and the distribution was dichotomized (median value: 2.86) into groups classified as high and low, with values ranging from $>2.86$ to 5.0 and from 1 to 2.86, respectively. The control index comprised eight out of nine suggested items: "opportunity to learn new things", "development of own abilities", "repetitive work", "creativity requirements", "high level of skill” "own decisions allowed", "little decision freedom" and "a lot of say". No information was available on the item "variety". The index varied between 1 and 6 , and the distribution was dichotomized into groups classified as high and low, with values ranging from 1 to 1.38 and from $>1.38$ to 6 , respectively (median: 1.38). The demand/control index has been widely used and internationally validated [32].

Adjustment latitude index [33] was measured using the question "What opportunities do you have for adjusting your work if you do not feel well?" The respondents were asked whether they could act in one of the following seven ways: do only necessary work and postpone the rest; choose among work tasks; get help from workmates; work at a slower pace than usual; take longer breaks; shorten the working day; go home and do the work later. The participants answered on a four-point scale (always, most of the 
time, mostly not, never), and the responses were summed to create an index. The index varied between 0 and 7 , and the distribution was trichotomized into groups classified as high, middle, and low, with values ranging from 6 to 7 , from 3 to 5, and from 0 to 2, respectively (median: 2.0). This instrument has been shown to correlate with both SP and SA [34], but to our knowledge it has not been validated in terms of psychometric characteristics.

\section{Predictors}

Self-reported sickness presence (SP) was measured using the question "Has it happened over the previous 12 months that you have gone to work despite feeling that you really should have taken sick leave because of your state of health?" The response options were as follows: no, never (1); yes, once (2); yes, 2-5 times (3); more than five times (4); have not been sick during the past 12 months (5). In the regression analyses, this scale was also dichotomized into:

- $0=$ have not been sick during the past 12 months / no, never / yes, once;

- $1=$ yes, $2-5$ times / more than five times.

Test-retest reliability for this question has been tested by Demerouti et al. [22], who reported the value of 0.58 $(p<0.01)$ or greater for 6-month and 12-month intervals. Self-reported sickness absence (SA) was measured using the question "How many days over the past 12 months have you been off work due to sickness (sick leave, receiving health care, under medical treatment, or under investigation)?" The response options were as follows: none (1); less than a week (2); 1-2 weeks (3); 2-4 weeks (4); 1-3 months (5); more than 3 months (6). Response categories 4, 5, and 6 were combined, and in the regression analyses this scale was dichotomized to $0=$ none/less than a week and 1 = one week or more. In the present study, the concordance between self-reported absence days and register data (LISA) on SA over 12 months was high, and estimated at $77 \%$ and $93 \%$ depending on the length of absence. This is in line with Voss et al. [35], who found data consistency between self-rated SA and register information on SA over a 12-month period and concluded that self-reported SA may be useful in epidemiological studies.

\section{Outcome factors}

General self-rated health (SRH) was measured using the question "How do you rate your general state of health?" The original five-digit scale was dichotomized into very good/rather good (good) and variable/rather poor/very poor (poor) [36]. To measure physical complaints, a fiveitem mean value index was used [37], which covered complaints about experiencing pain in the lower or upper back, the shoulders, the hips, and the wrists. Participants answered on a five-point scale (not at all/seldom, in the last three months, a couple of days a month, once a week, a couple of days a week, or every day). A mean value index was constructed that varied between 1 and 5 , and the distribution was dichotomized into groups classified as high and low, with values ranging from $>1.60$ to 5 and from 1 to 1.60 , respectively (median 1.6). The Work Ability Index (WAI) was scored using a five-item scale [38]. Participants responded to the following questions as indicated:

— "How many points would you give your current work ability?" - on a 10-point scale (completely unable to work — work ability at its best);

- "How do you rate your current work ability with respect to the physical demands of your job?" - on a 5-point scale (very good - very poor);

— "How do you rate your current work ability with respect to the mental demands of your job?" - on a 5-point scale (very good - very poor);

- "Do you believe that, from the standpoint of your health, you will be able to do your current job two years from now?" - on a 3-point scale (unlikely relatively certain); 
— "Is your disease or injury a hindrance in your current job?" - on a 6-item scale (There is no hindrance or/I have no diseases - in my opinion I am entirely unable to work).

A mean value index was constructed (scale 1 to 10 points). In the group classified as high, values ranged from 8.0 to 10 ; for low, the interval was 1 to 7.9 ; and the median value was 8.0. The WAI instrument has been found to have acceptable test-retest qualities [39].

"Mental well-being" was measured using a 10-item index [40], with responses given on a 4-point scale (never, sometimes, often, or always) to indicate how often the participant had experienced feeling any of the following during the last week: "downhearted and blue; calm and peaceful; energetic, active, or vigorous", "I have been waking up feeling fresh and rested, "I am happy, satisfied, or pleased with my personal life", "I am well-adjusted to my life situation", "I have lived the kind of life I wanted", "I have felt eager to tackle my daily tasks or make new decisions", "I have felt I could easily handle or cope with any serious problem or major change in my life", "My daily life has been full of things that were interesting to me".

A mean value index was constructed. In the group classified as high, values ranged from 1.0 to 2.2; for low, the interval was 2.3 to 4.0 ; and the median value was 2.3 . The index for mental well-being has been tested for internal and external validity and found to have acceptable characteristics [40].

\section{Analytical strategy}

In the first step, a description was provided. Chi ${ }^{2}$ tests based on cross-tabulations were calculated to identify significant background factors that might affect the predictors. This included the background factors mentioned, work-related factors, and factors associated with previous health at $\mathrm{T} 1$ and the predictors at T2. The aim was to control for such factors in the analysis of the effects of SP and SA.

In the second step, block-wise multiple logistic regression analyses were conducted for SP and SA, respectively, including controls for background factors and other confounders. Each set of confounders was introduced blockwise in five different models to make it possible to determine how the different factors affected the estimates of odds ratios for SP and SA. The crude odds ratios were calculated in Model 1, and sex, age, and education were controlled for in Model 2. Additional control for work-related factors was introduced in Model 3, and self-reported general health at T1 was added in Model 4. In Model 5, T1 values for the two outcome factors SP and SA were also controlled for, together with all other confounders.

\section{RESULTS}

Table 1 provides an overview of the distribution of SP and SA in 2005 (T2) in relation to background factors, work factors, and outcome factors in 2004 (T1).

Table 1. Self-reported sickness presence and sickness absence in 2005 related to background factors, work factors, and outcome factors at baseline in 2004, shown as percentage distribution

\begin{tabular}{|c|c|c|c|c|c|c|c|c|c|c|c|}
\hline \multirow{2}{*}{$\begin{array}{l}\text { Variable in } 2004 \\
\text { (T1) }\end{array}$} & \multirow[b]{2}{*}{$\mathrm{N}$} & \multicolumn{5}{|c|}{$\mathrm{SP}$ in 2005 (T2) } & \multicolumn{5}{|c|}{ SA in $2005(\mathrm{~T} 2)$} \\
\hline & & $\begin{array}{c}\text { never } \\
(\mathrm{n}=623)\end{array}$ & $\begin{array}{c}\text { once } \\
(\mathrm{n}=445)\end{array}$ & $\begin{array}{l}2-5 \text { times } \\
(\mathrm{n}=810)\end{array}$ & $\begin{array}{l}>5 \text { times } \\
(\mathrm{n}=303)\end{array}$ & $\mathrm{p}$ & $\begin{array}{c}0 \text { day } \\
(\mathrm{n}=738)\end{array}$ & $\begin{array}{l}<1 \text { week } \\
(\mathrm{n}=808)\end{array}$ & $\begin{array}{l}1-2 \text { weeks } \\
(\mathrm{n}=369)\end{array}$ & $\begin{array}{l}>3 \text { weeks } \\
(\mathrm{n}=264)\end{array}$ & $\mathrm{p}$ \\
\hline Total & 2181 & 28.6 & 20.4 & 37.1 & 13.9 & & 33.9 & 37.1 & 16.9 & 12.1 & \\
\hline \multicolumn{12}{|l|}{ Background } \\
\hline Sex & & & & & & 0.892 & & & & & $<0.001$ \\
\hline male & 1047 & 28.5 & 19.8 & 37.6 & 14.1 & & 35.9 & 39.4 & 16.2 & 8.5 & \\
\hline female & 1134 & 28.7 & 21.0 & 36.7 & 13.7 & & 32.0 & 35.0 & 17.6 & 15.4 & \\
\hline
\end{tabular}


Table 1. Self-reported sickness presence and sickness absence in 2005 related to background factors, work factors, and outcome factors at baseline in 2004, shown as percentage distribution - cont.

\begin{tabular}{|c|c|c|c|c|c|c|c|c|c|c|c|}
\hline \multirow{2}{*}{$\begin{array}{c}\text { Variable in } 2004 \\
\text { (T1) }\end{array}$} & \multirow[b]{2}{*}{$\mathrm{N}$} & \multicolumn{5}{|c|}{ SP in 2005 (T2) } & \multicolumn{5}{|c|}{ SA in 2005 (T2) } \\
\hline & & $\begin{array}{c}\text { never } \\
(\mathrm{n}=623)\end{array}$ & $\begin{array}{c}\text { once } \\
(\mathrm{n}=445)\end{array}$ & $\begin{array}{l}2-5 \text { times } \\
(\mathrm{n}=810)\end{array}$ & $\begin{array}{l}>5 \text { times } \\
(\mathrm{n}=303)\end{array}$ & $\mathrm{p}$ & $\begin{array}{c}0 \text { day } \\
(\mathrm{n}=738)\end{array}$ & $\begin{array}{l}<1 \text { week } \\
(\mathrm{n}=808)\end{array}$ & $\begin{array}{l}1-2 \text { weeks } \\
(\mathrm{n}=369)\end{array}$ & $\begin{array}{l}>3 \text { weeks } \\
(\mathrm{n}=264)\end{array}$ & $\mathrm{p}$ \\
\hline$\overline{\text { Age }}$ & & & & & & 0.010 & & & & & $<0.001$ \\
\hline $25-30$ & 393 & 26.5 & 23.4 & 35.4 & 14.8 & & 28.8 & 41.5 & 18.3 & 11.5 & \\
\hline $31-35$ & 381 & 27.0 & 23.4 & 38.8 & 10.8 & & 23.9 & 44.5 & 20.0 & 11.6 & \\
\hline $36-40$ & 473 & 27.7 & 16.1 & 43.1 & 13.1 & & 33.3 & 38.1 & 16.9 & 11.7 & \\
\hline $41-45$ & 450 & 29.1 & 21.8 & 32.2 & 16.9 & & 38.9 & 35.3 & 14.0 & 11.8 & \\
\hline $46-50$ & 484 & 31.8 & 18.6 & 36.0 & 13.6 & & 41.7 & 28.3 & 16.1 & 13.8 & \\
\hline Education & & & & & & $<0.001$ & & & & & $<0.001$ \\
\hline no university & 1174 & 27.9 & 17.2 & 37.7 & 17.1 & & 31.8 & 35.1 & 18.0 & 15.2 & \\
\hline university & 901 & 29.1 & 24.1 & 36.5 & 10.3 & & 36.6 & 40.3 & 15.2 & 7.9 & \\
\hline \multicolumn{12}{|l|}{ Work factors } \\
\hline SEI & & & & & & 0.008 & & & & & $<0.001$ \\
\hline blue-collar & 813 & 25.7 & 17.7 & 40.3 & 16.2 & & 30.6 & 33.9 & 18.6 & 16.9 & \\
\hline white-collar & 786 & 31.3 & 21.0 & 34.9 & 12.8 & & 34.7 & 36.0 & 18.1 & 11.2 & \\
\hline professionals & 392 & 28.1 & 23.7 & 36.0 & 12.2 & & 36.0 & 44.1 & 13.8 & 6.1 & \\
\hline Demands & & & & & & $<0.001$ & & & & & 0.002 \\
\hline low & 971 & 35.6 & 20.3 & 35.1 & 9.0 & & 32.3 & 38.2 & 18.9 & 10.5 & \\
\hline high & 881 & 20.4 & 20.1 & 40.6 & 18.8 & & 35.5 & 35.2 & 14.5 & 14.8 & \\
\hline Control & & & & & & 0.141 & & & & & $<0.001$ \\
\hline high & 899 & 28.8 & 22.4 & 36.6 & 12.2 & & 36.2 & 39.9 & 14.7 & 9.2 & \\
\hline low & 963 & 27.9 & 18.8 & 38.6 & 14.5 & & 31.0 & 34.2 & 19.5 & 15.3 & \\
\hline Adjust. latitude & & & & & & $<0.001$ & & & & & $<0.001$ \\
\hline low $(0-2 p)$ & 719 & 18.9 & 20.3 & 43.0 & 17.8 & & 32.2 & 34.7 & 18.2 & 14.9 & \\
\hline$(3-5)$ & 388 & 26.8 & 21.6 & 40.5 & 11.1 & & 26.0 & 43.3 & 18.3 & 12.4 & \\
\hline $\operatorname{high}(6-7 p)$ & 306 & 40.2 & 20.6 & 30.4 & 8.8 & & 43.5 & 37.3 & 14.1 & 5.2 & \\
\hline \multicolumn{12}{|l|}{ Outcome factors } \\
\hline Health & & & & & & $<0.001$ & & & & & $<0.001$ \\
\hline good & 775 & 38.5 & 23.0 & 30.3 & 8.3 & & 40.3 & 38.0 & 14.8 & 6.8 & \\
\hline poor & 1258 & 22.3 & 18.5 & 41.8 & 17.3 & & 29.0 & 36.3 & 19.0 & 15.7 & \\
\hline Phys. complaints & & & & & & $<0.001$ & & & & & $<0.001$ \\
\hline low & 1064 & 35.8 & 23.4 & 34.1 & 6.7 & & 38.9 & 39.2 & 14.6 & 7.3 & \\
\hline high & 902 & 19.3 & 17.6 & 41.5 & 21.6 & & 28.3 & 34.7 & 19.3 & 17.7 & \\
\hline Mental well-being & & & & & & $<0.001$ & & & & & $<0.001$ \\
\hline low & 992 & 21.1 & 19.2 & 41.7 & 18.0 & & 28.7 & 37.0 & 18.9 & 15.4 & \\
\hline high & 1026 & 35.7 & 22.2 & 32.7 & 9.4 & & 38.9 & 37.6 & 14.5 & 9.0 & \\
\hline
\end{tabular}


Table 1. Self-reported sickness presence and sickness absence in 2005 related to background factors, work factors, and outcome factors at baseline in 2004, shown as percentage distribution - cont.

\begin{tabular}{|c|c|c|c|c|c|c|c|c|c|c|c|}
\hline \multirow{2}{*}{$\begin{array}{l}\text { Variable in } 2004 \\
\text { (T1) }\end{array}$} & \multirow[b]{2}{*}{$\mathrm{N}$} & \multicolumn{5}{|c|}{ SP in 2005 (T2) } & \multicolumn{5}{|c|}{ SA in 2005 (T2) } \\
\hline & & $\begin{array}{c}\text { never } \\
(\mathrm{n}=623)\end{array}$ & $\begin{array}{c}\text { once } \\
(\mathrm{n}=445)\end{array}$ & $\begin{array}{l}2-5 \text { times } \\
(\mathrm{n}=810)\end{array}$ & $\begin{array}{l}>5 \text { times } \\
(\mathrm{n}=303)\end{array}$ & $\mathrm{p}$ & $\begin{array}{c}0 \text { day } \\
(\mathrm{n}=738)\end{array}$ & $\begin{array}{l}<1 \text { week } \\
(\mathrm{n}=808)\end{array}$ & $\begin{array}{l}1-2 \text { weeks } \\
(\mathrm{n}=369)\end{array}$ & $\begin{array}{l}>3 \text { weeks } \\
(\mathrm{n}=264)\end{array}$ & p \\
\hline Work ability & & & & & & $<0.001$ & & & & & $<0.001$ \\
\hline low & 844 & 18.1 & 16.8 & 44.0 & 21.1 & & 23.1 & 37.4 & 21.1 & 18.4 & \\
\hline high & 1019 & 36.5 & 23.7 & 32.7 & 7.1 & & 42.5 & 36.5 & 13.7 & 7.3 & \\
\hline SA & & & & & & $<0.001$ & & & & & $<0.001$ \\
\hline $\begin{array}{l}\text { none } \\
\text { or }<1 \text { week }\end{array}$ & 1399 & 32.1 & 21.6 & 35.5 & 10.8 & & 42.0 & 39.9 & 12.5 & 5.6 & \\
\hline$\geq 1$ week & 501 & 18.2 & 17.2 & 43.5 & 21.2 & & 10.6 & 27.8 & 30.0 & 31.6 & \\
\hline SP & & & & & & $<0.001$ & & & & & $<0.001$ \\
\hline none or once & 951 & 45.4 & 24.3 & 24.1 & 6.2 & & 42.0 & 39.9 & 12.5 & 5.6 & \\
\hline$\geq 2$ times & 951 & 11.5 & 16.5 & 51.3 & 20.7 & & 10.6 & 27.8 & 30.0 & 31.6 & \\
\hline
\end{tabular}

SEI — socioeconomic position; SA — sickness absence; SP — sickness presence.

A significant tendency towards high SP and high SA was observed among low-educated individuals, middle-aged persons, and blue-collar workers. There was no clear association between sex and SP, but a number of work factors were significantly related to both SP and SA. Table 1 further shows that psychological demands and adjustment latitude were correlated with both SP and SA. Control was significantly correlated with SA, but not with SP. As expected, SP and SA were also related to general health, physical complaints, work ability, mental well-being, and self-rated SP and SA during the previous year (T1).

It should be noted that individuals who reported SP at T3 also reported SA at T3 (Table not presented). This indicates that individuals with poor health throughout the three-year period reported both SP and SA in 2006. Thus, different aspects of ill health are interrelated and may not be easy to separate, even in a three-year period.

Table 2 presents the odds ratios for the impact that SP in 2005 had on the various outcome factors one year later. Crude ratios are presented in Model 1.

The odds ratios increased in a regular way for each point on the scale for SP. Significant effects $(\mathrm{p}<0.001)$, resulting in poor health, physical complaints, low mental wellbeing, low work ability, and SA, were apparent among the participants who had gone to work despite illness at least twice during the year. Furthermore, as expected, the greater the SP, the higher the odds ratios for health problems. These ratios changed very little when controls were introduced for age, sex, and education in Model 2, and this was also anticipated because the correlations with these variables and SP were generally weak.

In Model 3, adjustments were made for work factors, and there was an expected but not dramatic reduction in the odds ratios, which indicates that those factors did not markedly modify the effects of SP on the health outcomes, with the exception of mental well-being. When control for general health was introduced, as in Model 4, in most cases there was an expected and more evident reduction in the odds ratios. This means, not surprisingly, that general health influenced both SP and the health outcomes.

Both SA and SP were also controlled for in Model 5. The results show that the impact of SP remained significant for future low work ability, but, when SP was somewhat less frequent, it had no effect on general health, mental 
Table 2. Health consequences in 2006 of sickness presence in 2005

\begin{tabular}{|c|c|c|c|c|c|c|c|c|}
\hline \multirow{3}{*}{$\begin{array}{l}\text { Outcome factors in } 2006 \\
\text { (T3) }\end{array}$} & \multirow{3}{*}{ Model } & \multicolumn{7}{|c|}{ Predictor variable SP in 2005 (T2) } \\
\hline & & \multirow{2}{*}{$\begin{array}{c}\text { no, never } \\
(\mathrm{n}=308)\end{array}$} & \multicolumn{2}{|c|}{$\begin{array}{l}\text { yes, once } \\
(\mathrm{n}=255)\end{array}$} & \multicolumn{2}{|c|}{$\begin{array}{l}\text { yes, } 2-5 \text { times } \\
(\mathrm{n}=466)\end{array}$} & \multicolumn{2}{|c|}{$\begin{array}{l}\text { yes, }>5 \text { times } \\
(\mathrm{n}=167)\end{array}$} \\
\hline & & & OR & $\mathrm{CI}$ & OR & $\mathrm{CI}$ & OR & $\mathrm{CI}$ \\
\hline \multirow[t]{5}{*}{ Poor health } & 1 & 1 & 1.33 & $0.95-1.85$ & $2.19^{*}$ & $1.63-2.95$ & $3.65^{*}$ & $2.38-5.31$ \\
\hline & 2 & 1 & 1.38 & $0.98-1.63$ & $2.24^{*}$ & $1.66-3.02$ & $3.62 *$ & $2.35-5.57$ \\
\hline & 3 & 1 & 1.34 & $0.95-1.88$ & $2.14^{*}$ & $1.58-2.90$ & $3.41^{*}$ & $2.20-5.30$ \\
\hline & 4 & 1 & 1.23 & $0.84-1.79$ & 1.78 & $1.27-2.50$ & $2.76^{*}$ & $1.71-4.46$ \\
\hline & 5 & 1 & 1.19 & $0.81-1.75$ & 1.67 & $1.16-2.41$ & $2.53^{*}$ & $1.47-4.21$ \\
\hline \multirow[t]{5}{*}{ Physical complaints } & 1 & 1 & 1.73 & $1.20-2.48$ & $2.23^{*}$ & $1.62-3.06$ & $4.34^{*}$ & $2.86-6.60$ \\
\hline & 2 & 1 & 1.90 & $1.31-2.75$ & $2.36^{*}$ & $1.70-3.28$ & $4.24^{*}$ & $2.75-6.52$ \\
\hline & 3 & 1 & 1.76 & $1.20-2.57$ & $2.15^{*}$ & $1.54-3.01$ & $3.70^{*}$ & $2.38-5.75$ \\
\hline & 4 & 1 & 1.70 & $1.15-2.49$ & $1.93^{*}$ & $1.37-2.72$ & $3.23^{*}$ & $2.06-5.05$ \\
\hline & 5 & 1 & 1.60 & $1.08-2.37$ & 1.68 & $1.16-2.43$ & $2.67^{*}$ & $1.65-4.30$ \\
\hline \multirow[t]{5}{*}{ Low mental well-being } & 1 & 1 & 1.46 & $1.03-2.07$ & $1.74^{*}$ & $1.29-2.36$ & $3.58^{*}$ & $2.36-5.44$ \\
\hline & 2 & 1 & 1.49 & $1.05-2.11$ & $1.76^{*}$ & $1.29-2.38$ & $3.57^{*}$ & $2.34-5.43$ \\
\hline & 3 & 1 & 1.34 & $0.93-1.92$ & 1.53 & $1.11-2.10$ & $3.06^{*}$ & $1.99-4.70$ \\
\hline & 4 & 1 & 1.26 & $0.87-1.84$ & 1.28 & $0.92-1.78$ & $2.56^{*}$ & $1.63-4.03$ \\
\hline & 5 & 1 & 1.17 & $0.80-1.71$ & 1.10 & $0.77-1.57$ & 2.16 & $1.34-3.49$ \\
\hline \multirow[t]{5}{*}{ Low work ability } & 1 & 1 & 1.60 & $1.11-2.30$ & $3.02 *$ & $2.19-4.16$ & $5.25^{*}$ & $3.41-8.10$ \\
\hline & 2 & 1 & 1.67 & $1.15-2.42$ & $3.11^{*}$ & $2.25-4.31$ & $5.18^{*}$ & $3.34-8.01$ \\
\hline & 3 & 1 & 1.54 & $1.06-2.25$ & $2.84^{*}$ & $2.04-3.96$ & $4.56^{*}$ & $2.92-7.11$ \\
\hline & 4 & 1 & 1.48 & $1.00-2.18$ & $2.52^{*}$ & $1.78-3.55$ & $3.83^{*}$ & $2.42-6.08$ \\
\hline & 5 & 1 & 1.42 & $0.95-2.11$ & $2.31^{*}$ & $1.59-3.36$ & $3.28^{*}$ & $2.00-5.37$ \\
\hline \multirow{5}{*}{ Sickness absence (SA) } & 1 & 1 & 1.73 & $1.16-2.72$ & $2.60^{*}$ & $1.79-3.78$ & $3.51^{*}$ & $2.23-5.52$ \\
\hline & 2 & 1 & 1.76 & $1.14-2.72$ & $2.58^{*}$ & $1.76-3.76$ & $3.36^{*}$ & $2.12-5.32$ \\
\hline & 3 & 1 & 1.69 & $1.09-2.63$ & $2.45^{*}$ & $1.67-3.60$ & $3.19^{*}$ & $1.99-5.10$ \\
\hline & 4 & 1 & 1.64 & $1.06-2.55$ & $2.28^{*}$ & $1.55-3.36$ & $2.90^{*}$ & $1.80-4.66$ \\
\hline & 5 & 1 & 1.47 & $0.92-2.36$ & 1.75 & $1.13-2.71$ & 1.76 & $1.02-3.02$ \\
\hline
\end{tabular}

Data presented as crude and adjusted odds ratio (OR) and 95\% confidence intervals (CI).

* Significance $\mathrm{p}<0.001$.

Model 1: crude.

Model 2: adjusted for age, sex, and education (T1).

Model 3: additionally adjusted for adjustment latitude, psychological demands, and control (T1).

Model 4: additionally adjusted for general health (T1).

Model 5: additionally adjusted for SA and SP (T1).

well-being or physical complaints. Thus SP, and in particular frequent SP, had distinct health consequences, even after control for background factors, work factors, and previous health.
Table 3 shows the results of a corresponding analysis of the consequences of SA. In general, the odds ratios were lower than those found for SP, and they remained significant only for SA longer than three weeks after control 
Table 3. Health consequences in 2006 of self-rated sickness absence in 2005

\begin{tabular}{|c|c|c|c|c|c|c|c|c|}
\hline \multirow{3}{*}{$\begin{array}{l}\text { Outcome factors in } 2006 \\
\text { (T3) }\end{array}$} & \multirow{3}{*}{ Model } & \multicolumn{7}{|c|}{ Predictor variable SA in 2005 (T2) } \\
\hline & & \multirow{2}{*}{$\begin{array}{c}0 \text { day } \\
(\mathrm{n}=400)\end{array}$} & \multicolumn{2}{|c|}{$\begin{array}{l}<1 \text { week } \\
(\mathrm{n}=457)\end{array}$} & \multicolumn{2}{|c|}{$\begin{array}{l}1-2 \text { weeks } \\
(\mathrm{n}=205)\end{array}$} & \multicolumn{2}{|c|}{$\begin{array}{l}>3 \text { weeks } \\
(\mathrm{n}=133)\end{array}$} \\
\hline & & & OR & $\mathrm{CI}$ & OR & $\mathrm{CI}$ & OR & $\mathrm{CI}$ \\
\hline \multirow[t]{5}{*}{ Poor health } & 1 & 1 & $1.56^{*}$ & $1.19-2.05$ & $1.97^{*}$ & $1.38-2.80$ & $3.01^{*}$ & $1.92-4.70$ \\
\hline & 2 & 1 & $1.71^{*}$ & $1.29-2.26$ & $2.09^{*}$ & $1.46-3.00$ & $3.00^{*}$ & $1.90-4.73$ \\
\hline & 3 & 1 & $1.72^{*}$ & $1.30-2.28$ & $2.08^{*}$ & $1.45-2.99$ & $2.87^{*}$ & $1.82-4.54$ \\
\hline & 4 & 1 & 1.51 & $1.10-2.06$ & 1.66 & $1.11-2.48$ & 2.21 & $1.34-3.65$ \\
\hline & 5 & 1 & 1.46 & $1.07-2.00$ & 1.56 & $1.03-2.38$ & 2.04 & $1.19-3.52$ \\
\hline \multirow[t]{5}{*}{ Physical complaints } & 1 & 1 & 1.23 & $0.92-1.63$ & 1.57 & $1.09-2.25$ & $3.14^{*}$ & $2.07-4.77$ \\
\hline & 2 & 1 & 1.34 & $0.99-1.81$ & 1.53 & $1.05-2.22$ & $2.64^{*}$ & $1.72-4.06$ \\
\hline & 3 & 1 & 1.38 & $1.02-1.87$ & 1.51 & $1.03-2.22$ & $2.44^{*}$ & $1.58-3.79$ \\
\hline & 4 & 1 & 1.29 & $0.94-1.75$ & 1.34 & $0.91-1.98$ & 2.01 & $1.33-3.28$ \\
\hline & 5 & 1 & 1.20 & $0.88-1.65$ & 1.13 & $0.75-1.70$ & 1.60 & $0.98-2.62$ \\
\hline \multirow[t]{5}{*}{ Mental well-being } & 1 & 1 & 1.16 & $0.88-1.53$ & 1.31 & $0.92-1.86$ & $2.30^{*}$ & $1.52-3.47$ \\
\hline & 2 & 1 & 1.20 & $0.91-1.60$ & 1.34 & $0.93-1.91$ & $2.20^{*}$ & $1.45-3.35$ \\
\hline & 3 & 1 & 1.24 & $0.92-1.66$ & 1.26 & $0.87-1.83$ & 1.98 & $1.28-3.05$ \\
\hline & 4 & 1 & 1.09 & $0.80-1.48$ & 1.04 & $0.70-1.53$ & 1.52 & $0.97-2.40$ \\
\hline & 5 & 1 & 1.05 & $0.77-1.43$ & 0.96 & $0.64-1.45$ & 1.37 & $0.84-2.25$ \\
\hline \multirow[t]{5}{*}{ Low work ability } & 1 & 1 & 1.38 & $1.03-1.85$ & $2.47^{*}$ & $1.72-3.54$ & $4.38^{*}$ & $2.82-6.80$ \\
\hline & 2 & 1 & 1.48 & $1.10-2.00$ & $2.56^{*}$ & $1.77-3.69$ & $4.21^{*}$ & $2.69-6.58$ \\
\hline & 3 & 1 & 1.51 & $1.12-2.05$ & $2.57^{*}$ & $1.76-3.74$ & $3.93^{*}$ & $2.50-6.20$ \\
\hline & 4 & 1 & 1.36 & $0.99-1.86$ & $2.24^{*}$ & $1.51-3.31$ & $3.22^{*}$ & $2.01-5.18$ \\
\hline & 5 & 1 & 1.26 & $0.91-1.73$ & 1.86 & $1.23-2.81$ & $2.42^{*}$ & $1.45-4.05$ \\
\hline \multirow[t]{5}{*}{ Sickness presence (SP) } & 1 & 1 & 1.53 & $1.16-2.03$ & $1.88^{*}$ & $1.32-2.68$ & $2.93^{*}$ & $1.92-4.49$ \\
\hline & 2 & 1 & 1.53 & $1.15-2.04$ & $1.85^{*}$ & $1.29-2.65$ & $2.86^{*}$ & $1.86-4.39$ \\
\hline & 3 & 1 & 1.58 & $1.17-2.12$ & $1.92^{*}$ & $1.33-2.79$ & $2.66^{*}$ & $1.71-4.14$ \\
\hline & 4 & 1 & 1.47 & $1.09-1.98$ & 1.74 & $1.19-2.53$ & $2.28^{*}$ & $1.45-3.59$ \\
\hline & 5 & 1 & 1.29 & $0.94-1.78$ & 1.38 & $0.91-2.10$ & 1.57 & $0.94-2.63$ \\
\hline
\end{tabular}

Abbreviations as in Table 2.

for background factors, work factors and previous health. Work ability is the only outcome factor for which the odds ratios were just as high for SA as for SP. However, the relationships between SA and health outcomes were similar to those observed between SP and health outcomes, and they remained significant even after adjustment for background factors, work factors, and general health. Reporting frequent SA had a distinct effect on health outcomes.
The only exception to this pattern is that the association between SA and future SP was no longer significant after introduction of prior general health.

In summary, Tables 2 and 3 indicate that SA and SP had similar negative effects on the health indicators, and this was particularly pronounced among participants with frequent SP or SA. On the whole, it seems that SP is a strong predictor of the five negative health outcomes measured 
here and it also leads to an increased risk of future SA. However, the use of SP does not have a significant impact on future mental well-being, if prior health is taken into account. High odds ratios were evident for all health indicators one year after reporting SA, but when control for prior self-reported health was introduced, they remained significant only for low work ability and sickness SP. When prior SP and SA were added to the control factors, only work ability showed significant odds ratios.

\section{DISCUSSION}

This three-wave cohort study was conducted to analyze the effects of sickness presence and sickness absence on future health. The design of the investigation allowed the use of control variables, predictors and outcomes at different points in time, to avoid the possibility of correlation between some factors, which was particularly important when considering relationships with work factors and health. The results showed that both SP and SA appeared to be strong predictors of various indicators of ill health and work ability.

The introduction of controls for confounders related to individual factors and work factors did not change the mentioned results dramatically. However, as anticipated, adding prior self-reported general health as a control factor reduced the impact of both SP and SA. The negative health effects remained significant for the participants with the most frequent use of SP for three of the five health indicators. In case of those who had had only occasional SP, there were no significant effects on health one year later. Findings were similar for the group that had reported being on sick leave (SA) for less than three weeks during the year. Decline in work ability was the only health outcome that was also influenced by shorter SA even after control for confounders. These results were interpreted as demonstrating that particularly frequent SP and SA had distinct and similar negative health consequences. The data also suggests that there was a dose-response relationship between the degree of SA and SP and the different health outcomes, since it is apparent that the stronger and more robust the results, the greater the extent of SA and SP among the study participants under consideration. The present findings confirm a recent study by Hansen and Andersen [41], which showed that repeated SP increased the risk of future SA. Similarly, Bergstrom et al. [23,24] found that, even after control for previous health status, frequent SP had a significant impact on self-reported health in public- and private-sector employees at the 18-month and 3-year follow-ups. Two investigations have compared SP and SA [5,28], but they focused on causes rather than consequences, and they were cross-sectional in design. Both those studies indicated that explanatory factors for SP and SA differ, at least to some extent. Even if this is the case, our results suggest that similar negative effects on health are exerted by frequent SP and frequent SA. The observation in the present study that SP was associated with reduced work ability, is congruent with a few earlier studies [6].

\section{Methodological considerations}

The strengths of this study were the longitudinal design, the relatively large data set, and the fact that the analyses were based on a representative sample of the Swedish working population. Furthermore, the three-wave design made it possible to control for a number of variables at the different time points considered in the statistical analyses. Although it may be regarded as excessive control, we chose to take self-rated health, SA, and SP at T1 (2004) into account in one of the multiple logistic models. This was done in an attempt to control for differences in initial health in the study population.

However, this data material also has its limitations. First, the number of respondents was reduced due to non-participation and selection bias. The low response rate may introduce a bias, since healthy persons are more likely to participate than those with health problems. Second, 
non-response to some of the questions also lowered the total number of respondents in the final multiple logistic regression analysis. No imputations were used to reduce this problem, to avoid other errors being introduced. Third, the use of single-item self-reported measures on SP and SA for the last 12 months may lead to recall bias. However, a high level of agreement was found between self-reported and register data over 12 months on SA in the present study. Voss et al. [35] also found good agreement between self-reported SA and register information on SA for Swedish conditions. However, some uncertainty remains. Based on Dutch experience, Severens et al. [42] and Poppel et al. [43] recommend a recall period of no more than two months for self-reported SA or the use of company information on SA. Due to the use of different response scales in the measurements of SP and SA, it was also difficult to compare the odds ratios.

The current results indicate that a number of issues should be addressed in future studies. Efforts should be focused on persons with frequent SP and SA, to determine what characterizes members of that group and to ascertain the health consequences of SP and SA for those individuals. It would also be of interest to study the consequences of combined use of SP and SA. Another matter of interest is related to occupational conditions and differences between industries and sectors with respect to high and low levels of SP and SA. The third issue concerns the effect of family composition and demands in private life on people with SP and SA. Furthermore, research should be done to determine the degree to which the choice between SP and SA is affected by employees' income, employers' compensation of absence, and social security arrangements. Clearly, there is also a need to further develop and validate the measures of SP and SA. The relationship between low work ability and SA may in turn lead to disability pension [13].

The occurrence of SA is dictated by formal requirements such as a medical certificate and it does not always depend on the employee's decision. On the other hand, sickness presence is solely due to the employee's decision to start work despite the disease and it may relate to some specific medical conditions (e.g., allergies, migraines, rheumatism), as discussed in the work of Schultz and Edington [4]. For this reason, the results obtained in the study indicate that SP has a connection with future SA, while SA does not affect future SP (SP-related conditions have the effect in the next year as SA, i.e., worse or more severe disease states). Hence, after the introduction of controlling factors into the model, SA showed only influence on the deterioration in the work ability the following year, because these variables are highly correlated. Given the foregoing, the model presented by Johns [1] seems closer to reality in comparison with the model of Aronsson and Gustafsson [8].

\section{CONCLUSIONS}

In general, it seemed that SP had negative effects on all five health outcomes. The detrimental influence of frequent SP was most pronounced in relation to work ability and physical complaints, although all of the measured health factors were affected. SP also proved to be associated with future SA, whereas SA had no apparent impact on future SP. The effects of SA on future health were also pronounced, but after control for background factors, work factors and initial health, the only significant decrease shown was in work ability.

\section{REFERENCES}

1. Johns G. Presenteeism in the workplace: A review and research agenda. J Organiz Behav 2010;31:519-42.

2. Aronsson G, Gustafsson K, Dallner M. Sick but yet at work. An empirical study of sickness presenteeism. J Epidemiol Community Health 2000;54:502-9.

3. Elstad JI, Vabo M. Job stress, sickness absence and sickness presenteeism in Nordic elderly care. Scand J Public Health 2008;36:467-74. 
4. Schultz AB, Edington DW. Employee health and presenteeism: a systematic review. J Occup Rehabil 2007;17:547-79.

5. Bockerman P, Laukkanen E. What makes you work while you are sick? Evidence from a survey of workers. Eur J Public Health 2009;12:43-6.

6. Burton WN, Chen CY, Conti DJ, Schultz AB, Pransky G, Edington DW. The Association of Health Risks With On-theJob Productivity. J Occup Environ Med 2005;47:769-77.

7. Boles M, Pelletier B, Lynch W. The relationship between health risks and work productivity. J Occup Environ Med 2004;46:737-45.

8. Aronsson G, Gustafsson K. Sickness presenteeism: prevalence, attendance-pressure factors, and an outline of a model for research. J Occup Environ Med 2005;47:958-66.

9. Caverley N, Cunningham JB, MacGregor JN. Sickness presenteeism, sickness absenteeism, and health following restructuring in a public service organization. J Manag Stud 2007;44:304-19.

10. Aronsson G, Gustafsson K, Mellner C. Sickness Presence, Sickness Absence, and Self-reported Health and Symptoms. Int J Workplace Manag. In press 2011.

11. Stewart WF, Ricci JA, Chee E, Morganstein D. Lost productive work time costs from health conditions in the United States: results from the American Productivity Audit. J Occup Environ Med 2003;45:1234-46.

12. Koopman C, Pelletier KR, Murray JF, Sharda CE, Berger ML, Turpin RS, et al. Stanford presenteeism scale: health status and employee productivity. J Occup Environ Med 2002;44:14-20.

13. Vingard E, Alexanderson K, Norlund A. Swedish Council on Technology Assessment in Health Care (SBU). Chapter 9. Consequences of being on sick leave. Scand J Public Health Suppl 2004;63:207-15.

14. Ockander MK, Timpka T. A female lay perspective on the establishment of long-term sickness absence. Int J Soc Welfare 2001;10:74-9.

15. Ockander MK, Timpka T. Women's experiences of long term sickness absence: implications for rehabilitation practice and theory. Scand J Public Health 2003;31:143-8.
16. Judiesch M, Lyness K. Left behind? The impact of leaves of absence on managers career success. Acad Manag J 1999;42:641-51.

17. Bryngelson A. Long-term sickness absence and social exclusion. Scand J Public Health 2009;37:839-45.

18. Floderus B, Goransson S, Alexanderson K, Aronsson G. Self-estimated life situation in patients on long-term sick leave. J Rehabil Med 2005;37:291-9.

19. Kivimaki M, Head J, Ferrie JE, Hemingway H, Shipley MJ, Vahtera J, et al. Working while ill as a risk factor for serious coronary events: The Whitehall II study. Am J Public Health 2005;95:98-102.

20. Westerlund H, Kivimaki M, Ferrie JE, Marmot M, Shipley MJ, Vahtera J, et al. Does working while ill trigger serious coronary events? The Whitehall II study. J Occup Environ Med 2009;51:1099-104.

21. Hansen CD, Andersen JH. Sick at work - a risk factor for long-term sickness absence at a later date? J Epidemiol Community Health 2009;63:397-402.

22. Demerouti E, Le Blanc PM, Bakker AB, Schaufeli WB, Hox J. Present but sick: a three-wave study on job demands, presenteeism and burnout. Career Develop Int 2009;14:50-68.

23. Bergstrom G, Bodin L, Hagberg J, Aronsson G, Josephson M. Sickness presenteeism today, sickness absenteeism tomorrow? A prospective study on sickness presenteeism and future sickness absenteeism. J Occup Environ Med 2009;51: 629-38.

24. Bergstrom G, Bodin L, Hagberg J, Lindh T, Aronsson G, Josephson M. Does sickness presenteeism have an impact on future general health? Int Arch Occup Environ Health 2009;82(10):1179-90.

25. Ferrie JE, Vahtera J, Kivimaki M, Westerlund H, Melchior M, Alexanderson K, et al. Diagnosis-specific sickness absence and all-cause mortality in the GAZEL study. J Epidemiol Community Health 2009;63:50-5.

26. Vahtera J, Westerlund H, Ferrie JE, Head J, Melchior M, Singh-Manoux A, et al. All-cause and diagnosis-specific sickness absence as a predictor of sustained sub-optimal health: a 14-year follow-up in the GAZEL cohort. J Epidemiol Community Health 2009;64(4):311-7. 
27. Engstrom LG, Janson S. Predictors of work presence - Sickness absence in a salutogenic perspective. Work 2009;33:287-95.

28. MacGregor JN, Cunningham JB, Caverley N. Factors in absenteeism and presenteeism: life events and health events. Manag Res News 2008;31:607-15.

29. Marklund S, Berntson E, Bolin M, Harenstam A, Ylander J. Changing organisations and work-related health. Technical report of methods, sample and design of three studies. Arbetslivsrapport 2006:47. Stockholm: National Institute for Working Life; 2006.

30. Karasek Jr RA. Job Demands, Job Decision Latitude, and Mental Strain: Implications for Job Redesign. Admin Sci Q 1979;24:285-308.

31. Karasek R, Theorell T. Healhty work. Stress, Productivity and the Reconstruction of Working Life. New York: Basic Books; 1990.

32. Karasek R, Brisson C, Kawakami N, Houtman I, Bongers P, Amick B. The Job Content Questionnaire (JCQ): an instrument for internationally comparative assessments of psychosocial job characteristics. J Occup Health Psychol 1998;3:322-55.

33. Johansson G. The illness flexibility model and sickness [dissertation]. Stockholm: Karolinska Institutet; 2007.

34. Johansson G, Lundberg I. Adjustment latitude and attendance requirements as determinants of sickness absence or attendance. Empirical tests of the illness flexibility model. Soc Sci Med 2004;58:1857-68.

35. Voss M, Stark S, Alfredsson L, Vingard E, Josephson M. Comparisons of self-reported and register data on sickness absence among public employees in Sweden. Occup Environ Med 2008;65:61-7.

36. Bjorner JB, Søndergaard-Kristensen T, Orth-Gomér K, Tibblin G, Sullivan M, Westerholm P. Self-rated health - a useful concept in research, prevention and clinical medicine. Uppsala: Forskningsrådsnämnden; 1996.

37. Statistics Sweden. Labour force surveys. Stockholm: Statistics Sweden; 2002.

38. Tuomi K, Ilmarinen J, Jahkola A, Katajrinne L, Tulkki A. Work ability index. Helsinki: Institute of Occupational Health. Helsinki: Finnish Institute of Occupational Health; 1997.

39. de Zwart BC, Frings-Dresen MH, van Duivenbooden JC. Test-retest reliability of the Work Ability Index questionnaire. Occup Med (Lond) 2002;52:177-81.

40. Bech P, Gudex C, Staehr Johansen K. The WHO (Ten) well-being index: validation in diabetes. Psychother Psychosom 1996;65:183-90.

41. Hansen CD, Andersen JH. Going ill to work - what personal circumstances, attitudes and work-related factors are associated with sickness presenteeism? Soc Sci Med 2008;67:956-64.

42. Severens JL, Mulder J, Laheij RJ, Verbeek AL. Precision and accuracy in measuring absence from work as a basis for calculating productivity costs in The Netherlands. Soc Sci Med 2000;51(2):243-9.

43. van Poppel MN, de Vet HC, Koes BW, Smid T, Bouter LM. Measuring sick leave: a comparison of self-reported data on sick leave and data from company records. Occup Med (Lond) 2002;52:485-90.

This work is available in Open Access model and licensed under a Creative Commons Attribution-NonCommercial 3.0 Poland License - http://creativecommons.org/ licenses/by-nc/3.0/pl/deed.en. 